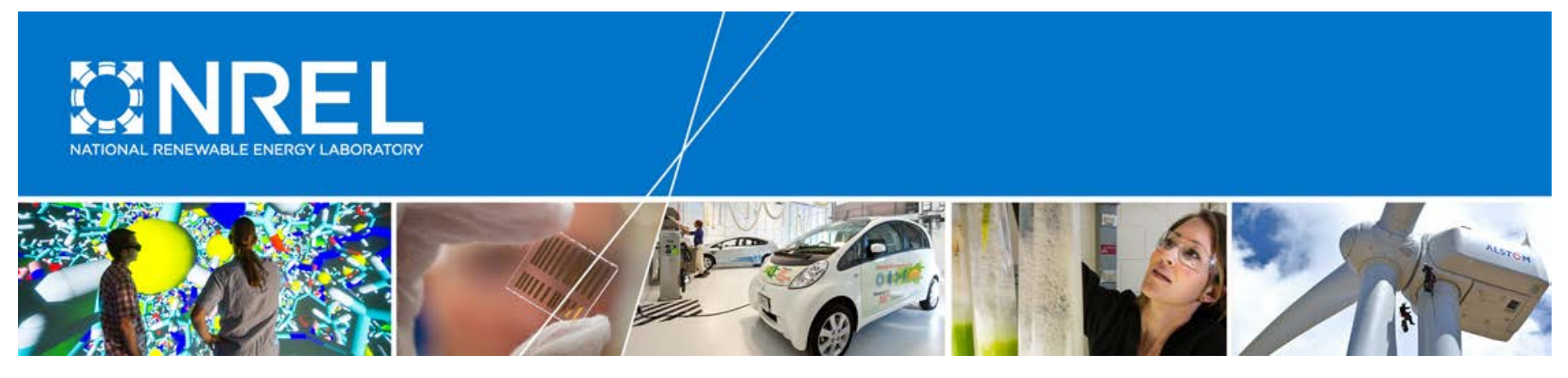

\title{
Optimized Generator Designs for the DTU 10-MW Offshore Wind Turbine using GeneratorSE
}

\section{Preprint}

Latha Sethuraman, Michael Maness, and Katherine Dykes National Renewable Energy Laboratory

To be presented at the American Institute of Aeronautics and Astronautics $35^{\text {th }}$ Wind Energy Symposium Grapevine, Texas

January 9-13, 2017

NREL is a national laboratory of the U.S. Department of Energy Office of Energy Efficiency \& Renewable Energy Operated by the Alliance for Sustainable Energy, LLC

This report is available at no cost from the National Renewable Energy Laboratory (NREL) at www.nrel.gov/publications.

Conference Paper

NREL/CP-5000-67444

January 2017

Contract No. DE-AC36-08GO28308 


\section{NOTICE}

The submitted manuscript has been offered by an employee of the Alliance for Sustainable Energy, LLC (Alliance), a contractor of the US Government under Contract No. DE-AC36-08GO28308. Accordingly, the US Government and Alliance retain a nonexclusive royalty-free license to publish or reproduce the published form of this contribution, or allow others to do so, for US Government purposes.

This report was prepared as an account of work sponsored by an agency of the United States government. Neither the United States government nor any agency thereof, nor any of their employees, makes any warranty, express or implied, or assumes any legal liability or responsibility for the accuracy, completeness, or usefulness of any information, apparatus, product, or process disclosed, or represents that its use would not infringe privately owned rights. Reference herein to any specific commercial product, process, or service by trade name, trademark, manufacturer, or otherwise does not necessarily constitute or imply its endorsement, recommendation, or favoring by the United States government or any agency thereof. The views and opinions of authors expressed herein do not necessarily state or reflect those of the United States government or any agency thereof.

This report is available at no cost from the National Renewable Energy Laboratory (NREL) at www.nrel.gov/publications.

Available electronically at SciTech Connect http:/www.osti.gov/scitech

Available for a processing fee to U.S. Department of Energy and its contractors, in paper, from:

U.S. Department of Energy

Office of Scientific and Technical Information

P.O. Box 62

Oak Ridge, TN 37831-0062

OSTI http://www.osti.gov

Phone: 865.576.8401

Fax: 865.576.5728

Email: reports@osti.gov

Available for sale to the public, in paper, from:

U.S. Department of Commerce

National Technical Information Service

5301 Shawnee Road

Alexandria, VA 22312

NTIS http://www.ntis.gov

Phone: 800.553 .6847 or 703.605 .6000

Fax: 703.605.6900

Email: orders@ntis.gov 
Optimized Generator Designs for the DTU 10-MW Offshore Wind Turbine using GeneratorSE

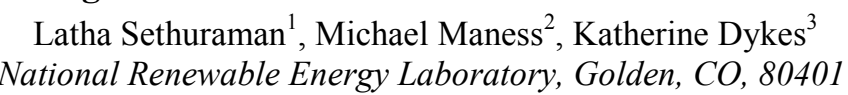

Compared to land-based applications, offshore wind imposes challenges for the development of next generation wind turbine generator technology. Direct-drive generators are believed to offer high availability, efficiency, and reduced operation and maintenance requirements; however, previous research suggests difficulties in scaling to several megawatts or more in size. The resulting designs are excessively large and/or massive, which are major impediments to transportation logistics, especially for offshore applications. At the same time, geared wind turbines continue to sustain offshore market growth through relatively cheaper and lightweight generators. However, reliability issues associated with mechanical components in a geared system create significant operation and maintenance costs, and these costs make up a large portion of overall system costs offshore. Thus, directdrive turbines are likely to outnumber their gear-driven counterparts for this market, and there is a need to review the costs or opportunities of building machines with different types of generators and examining their competitiveness at the sizes necessary for the next generation of offshore wind turbines. In this paper, we use GeneratorSE, the National Renewable Energy Laboratory's newly developed systems engineering generator sizing tool to estimate mass, efficiency, and the costs of different generator technologies satisfying the electromagnetic, structural, and basic thermal design requirements for application in a very large-scale offshore wind turbine such as the Technical University of Denmark's (DTU) 10-MW reference wind turbine. For the DTU reference wind turbine, we use the previously mentioned criteria to optimize a direct-drive, radial flux, permanent-magnet synchronous generator; a direct-drive electrically excited synchronous generator; a medium-speed permanent-magnet generator; and a high-speed, doubly-fed induction generator. Preliminary analysis of leveled costs of energy indicate that for large turbines, the cost of permanent magnets and reliability issues associated with brushes in electrically excited machines are the biggest deterrents for building direct-drive systems. The advantage of medium-speed permanent-magnet machines over doubly-fed induction generators is evident, yet, variability in magnet prices and solutions to address reliability issues associated with gearing and brushes can change this outlook. This suggests the need to potentially pursue fundamentally new innovations in generator designs that help avoid high capital costs but still have significant reliability related to performance.

\section{Nomenclature}

$\begin{array}{ll}b_{m} & =\text { magnet width }(\mathrm{mm}) \\ b_{p} & =\text { pole width }(\mathrm{mm}) \\ b_{p c} & =\text { pole core width }(\mathrm{mm}) \\ \mathrm{g} & =\text { air-gap length }(\mathrm{mm}) \\ h_{m} & =\text { magnet height }(\mathrm{mm}) \\ h_{p c} & =\text { pole core height }(\mathrm{mm}) \\ h_{p s} & =\text { pole shoe width }(\mathrm{mm}) \\ h_{s} & =\text { slot height }(\mathrm{mm}) \\ l & =\text { core length }(\mathrm{m}) \\ r_{s} & =\text { air-gap radius }(\mathrm{m}) \\ \tau_{p} & =\text { pole pitch }(\mathrm{mm}) \\ t & =\text { rotor back iron thickness }(\mathrm{mm})\end{array}$

\footnotetext{
${ }^{1}$ Postdoctoral researcher, National Wind Technology Center, MS 3811

${ }^{2}$ Analyst I, multidiscipline, Strategic Energy Analysis Center, MS 3811

${ }^{3}$ Senior engineer, National Wind Technology Center, MS 3811
} 


$\begin{array}{ll}t_{s} & =\text { stator back iron thickness }(\mathrm{mm}) \\ N_{p} & =\text { pole pairs } \\ R_{\mathrm{o}} & =\text { shaft radius }(\mathrm{m}) \\ \sigma & =\text { shear stress }\left(\mathrm{N} / \mathrm{m}^{2}\right) \\ V a l_{T C} & =\text { cost objective }\end{array}$

Note: Further definitions for symbols are available in their respective tables

\section{Introduction}

$\mathrm{D}$ uring the last 30 years, the wind industry has witnessed a steady trend toward larger wind turbines, with turbines rated $5 \mathrm{MW}$ or more common in the newer installations of the European offshore fleet [1]. As newer generations of larger turbines, rated 7-8 MW, are currently being developed and installed offshore [2], research efforts are being undertaken to address the challenges of unfavorable increases in weight and load that accompany this upscaling [3], [4]. Upscaling impacts the individual components in a the wind turbine, especially the drivetrain, which has implications on the overall nacelle mass, efficiency, reliability, and costs of generation. Mcdonald and Keysan [5] suggested that approximately $28 \%$ of the cost of energy for a typical wind power plant can be attributed to the choice of the drivetrain configuration, and technologies that reduce operation and maintenance (O\&M) costs will have the biggest impacts.

As part of the INNWIND initiative [4], which targets the feasibility of turbines rated 10-20 MW and more, the Technical University of Denmark (DTU) 10-MW reference model [6] presents the basic design details for an optimized light rotor turbine. The model serves as a useful reference to understand the structural dynamics of the blades, tower, and drivetrain besides understanding the rotor performance and its interaction with the rest of the system. The DTU 10-MW reference turbine assumes a medium-speed permanent-magnet generator with an estimated efficiency of $94 \%$. In terms of power conversion, several options are available [7], yet it is anticipated that direct-drive turbines with permanent-magnet generators will have the highest availability offshore [8]. According to INNWIND's performance-indicator-based assessment of innovative concepts [9], conventional geared-system and direct-drivegenerators are reported to have poor upscaling potentials at the 10-MW level. The INNWind study also showed that new, innovative drivetrain configurations can result in lightweight designs that are attractive for their lower prospective costs. The findings were based on scaling law models developed in previous research such as WindPACT [10] which is limited in its applicability at higher power levels because detailed design and optimization studies have not yet been carried out and inconsistencies exist in gearbox mass estimates (e.g., the estimated gearbox mass for a conventional high-speed drivetrain at $10 \mathrm{MW}$ using scaling law model [10] was 76 tons, whereas the mass model obtained by upscaling a 5-MW geared system was 178 tons). Also, no distinction is available on whether the direct-drive generator models were permanent magnet or electrically excited. It is known that the mass of direct-drive wind turbine generators scales disproportionately with turbine size because structural support requirements dominate the overall mass as the torque levels increase [11,12]. Considering the availability of few commercial generators rated $5 \mathrm{MW}$ or more with masses ranging between 100 and 220 tons [13-16], the scalability of these machines remains doubtful. At the same time, the pursuit of higher turbine ratings has been realized by geared, doubly-fed induction generators (DFIGs) that are substantially cheaper than direct-drive systems.

Efforts to optimize iron-cored, permanent-magnet synchronous generators (PMSGs) and electrically excited synchronous generators (EESGs) at the multimegawatt levels were carried out in [17]-[25]. A large inconsistency remains in the total estimated mass of the generators at the 10-MW level, with academic designs and scaling models [21], [25]-[28] suggesting a range between 200-500 t. Lighter weight designs were proposed in [29], yet some of these are academic, still provisional, or it is not clear how the masses scale. As novel, high-energy-density permanent magnets begin to emerge in the market, newer opportunities have emerged to offset the need to scale dimensions to achieve higher input torque; therefore, it is a worthwhile exercise to revisit the upscaling potential of these generators. Although EESGs are a mature technology, with widespread application exceeding $10 \mathrm{MW}$ [30], they are less popular in the offshore wind market. Many studies have discounted them for their lower efficiency and LCOE potentials [23] and high failure rates attributed to slip rings and brushes [31]. The largest known EESG is Enercon's E-126, which is $7.5 \mathrm{MW}$ and weighs 220 t. Reference [21] estimated a total mass of a similar EESG to be $340 \mathrm{t}$ at $10 \mathrm{MW}$, which is obviously too large when compared to permanent-magnet generators. Thus far, the impact of upscaling these machines has not been clearly established, and it is still unknown how the structural mass evolves as the power grows. In terms of geared systems, high-speed drives with three-stage gearboxes feeding double fed 
induction generators(DFIG-HS) are the most common configuration, with 10-MW machines only proposed as additions to some manufacturer's portfolios [32]. Of late, medium-speed permanent-magnet generators with singlestage gearboxes (PMSG-MS) are gaining popularity, with an increasing number of original equipment manufacturers opting for this configuration in large-scale offshore wind turbines with considerable weight saving, high annual energy production, and lowest levelized cost of energy (LCOE) potentials anticipated to be some of the main reasons [33], [34].

To better assess the effects of upscaling on generator designs, the weight and size of the generator subcomponents should be estimated using more meticulous approaches involving analytical tools, by using a finite-element method, or by building the machine. The latter methods can be time consuming and cost prohibitive; thus, in this paper, we use GeneratorSE [35], the National Renewable Energy Laboratory's (NREL's) newly developed systems engineering tool for sizing generators of different common topologies. It provides the user the opportunity to develop and customize generator designs that satisfy specific requirements and to estimate the mass of materials involved in the basic design and the costs of building them, and to compute the efficiency with relatively low computational effort. Four different generator designs were optimized for the DTU 10-MW reference turbine: a PMSG, EESG, PMSG-MS, and a DFIG-HS. A radial flux, surface-mounted, permanent-magnet machine of innerrotor-type construction was assumed for deriving the geometric and electromagnetic properties of the PMSG. Spoked-arm construction, as suggested by [36], was assumed for both the PMSG and EESG to arrive at the lightweight design. The electromagnetic and structural designs were validated using ANSYS and FEMM4.2 [37]. Results demonstrating their LCOE potentials are presented to facilitate the preliminary comparison of the design configurations at the 10 -MW scale.

\section{Design Optimization Using GeneratorSE}

GeneratorSE is an open-source Multidisciplinary Design Analysis and Optimization-based [38] generator sizing tool that considers available torque, mechanical power, normal and shear stresses, material properties, and costs to customize designs of variable-speed wind generators. GeneratorSE:

- Integrates electromagnetic, structural, and basic thermal designs of the generator and provides the optimal design dimensions by trading off active and inactive materials to satisfy certain fundamental and interdependent factors, such as weight, costs, or efficiency.

- Contains two modules featuring synchronous machines (PMSG and EESG) and two modules featuring induction machines (squirrel-cage and DFIG).

- Provides basic design attributes in addition to key electrical performance parameters-including but not limited to output voltage, current, resistances, inductances, and losses-and also the weights and costs of materials involved in the basic design.

- Allows for an integrated design with NREL's DriveSE[39] and NREL's cost and scaling models [40], thereby enabling a complete drivetrain optimization of direct-drive, medium-speed, and high-speed geared systems considering the entire turbine system and balance of plant.

A set of design parameters is chosen as decision variables based on which design is most sensitive (e.g., the air-gap radius and core length are design variables that determine the air-gap volume required to generate the torque), and the optimal design is searched by mathematical methods (linear and nonlinear programming or evolutionary plans based on genetic algorithms). The present study uses PMSG, EESG, and DFIG modules.

\section{PMSG and EESG Design Optimization}

In determining the main generator parameters for the active part, we use analytical models derived from conventional magnetic circuit laws [41]. Details of the electromagnetic models and design approach are available in [35]. For both generators, the stator designs in terms of slot and tooth geometry are identical with single layer fullpitch integer slot winding. The stator slots are assumed to be open rectangular, with one and two slots per pole per phase for the PMSG and EESG, respectively, with $65 \%$ coil fill factor in accordance with standard design practices [41]. Thermal design is accommodated as a secondary attribute by limiting the winding current densities to 3-6 $\mathrm{A} / \mathrm{mm}^{2}$ and specific current loading to $60 \mathrm{kA} / \mathrm{m}$. These limits are subject to change depending on the type of cooling and heat dissipation design and are expected to influence the generator design and overall mass. For the present designs, indirect air-cooling was assumed with permissible values chosen based on recommendations in [42]. A more stringent limit can stipulate the use of larger conductor cross-section. The additional active material for the 
PMSG comes from magnets mounted on the surface of the rotor and salient pole rotor with a DC field winding. The EESG requires a slightly different treatment for the rotor support structure design.

For the electromagnetic design optimization of the PMSG, the stator length and air-gap radius are adjusted to get the correct air-gap volume required to overcome the shear stress, $\sigma$. The magnet height and pole pitch determine the number of pole pairs required to generate a certain air-gap flux density (in the range of 0.7-1.2 Tesla) while also limiting the root-mean-square value of phase voltage to within $5 \mathrm{kV}$ and avoid tooth saturation.

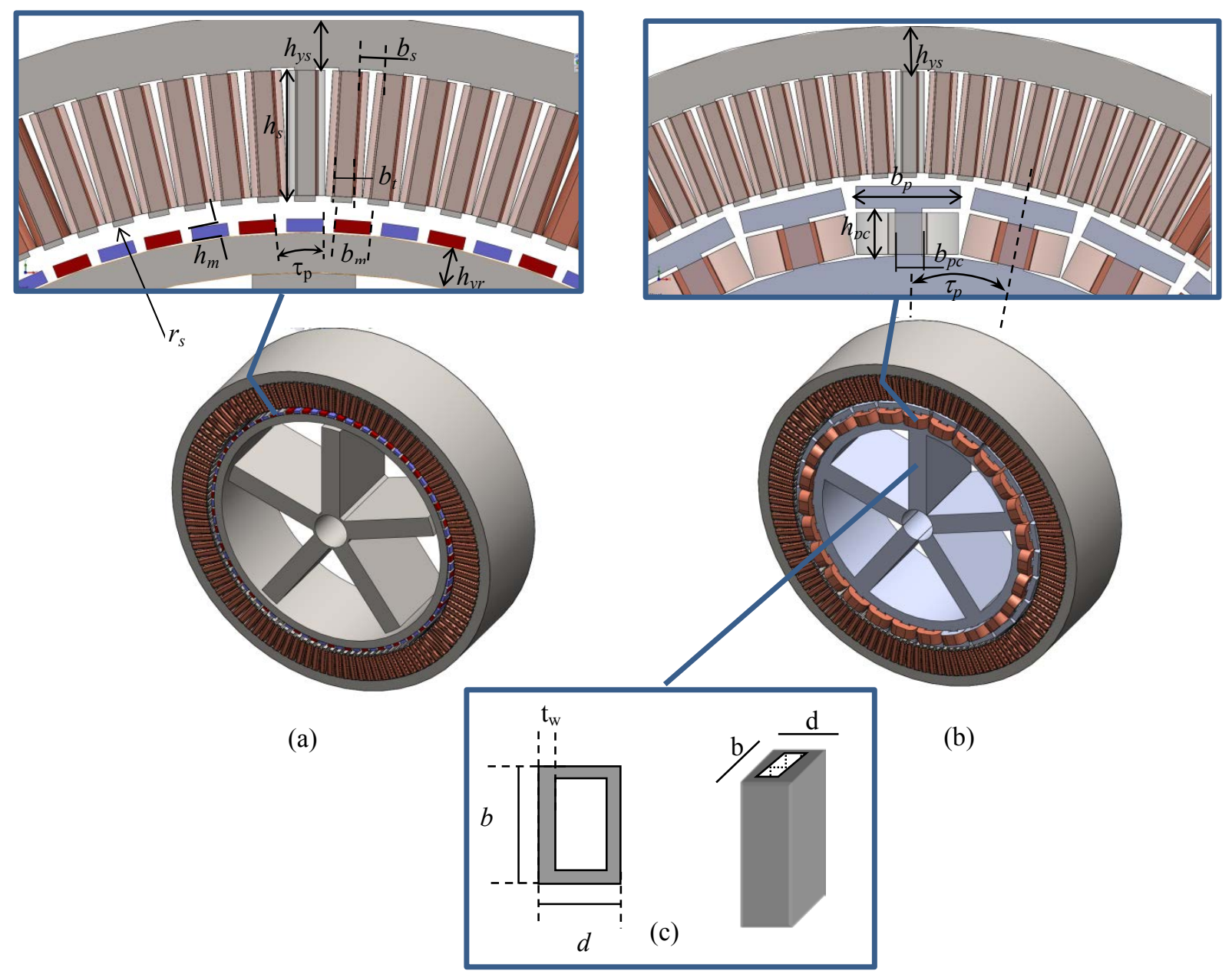

Figure 1. Computer-aided design illustrations of direct-drive generators showing the dimensions:

(a) PMSG and (b) EESG

To determine the optimal support structure, the analytical models for spoked-arm construction presented in [36] were used to arrive at a design that is lightweight yet also ensures adequate stiffness. These structures are characterized by a wheel-type arrangement (as shown in Figure 1), with spokes (arms) as reinforcements. These models account for the most important forces in the electrical machine; if they are not carefully treated, they can endanger the air-gap clearance, which is typically $1 / 1000^{\text {th }}$ of the air-gap diameter [20]. These include the normal component of Maxwell's stress acting along the circumference of the rotor and stator, centripetal force from the torque, $T$, and the acceleration as a result of gravity, which acts in the vertical direction. All calculations for the stator and rotor support structure deflections (radial component denoted by $U$, axial component denoted by $Y$, and circumferential component denoted by $Z$ ) are consistent with [36]. The adequacy of the structural design was verified by constraining the deflections to acceptable levels as suggested in [11]; the permissible values were $10 \%$ of the air-gap clearance for the total radial deflection in the air gap due to Maxwell stress, $0.2 \%$ of the axial length for the gravitational deflection, and a relative twist of $0.05^{\circ}$ for torsional deflection. 
For the EESG, the air-gap volume for the optimum electromagnetic design is decided by the need to overcome maximum shear stress. The rotor-winding magneto-motive force (mmf) or ampere-turns (field-winding turns, $N_{f}$, and field current, $I_{f}$ ) decide the conductor cross section and hence the resistance of the field winding. The values are so chosen to achieve a certain required peak air-gap flux density without exceeding the generator output phase voltage by $5 \mathrm{kV}$. The field current is limited such that the total excitation power is less than $1 \%$ of the power rating [39]. The structural optimization follows the same approach as the PMSG. For the EESG, to determine the weight of the rotor cylinder support structure, the weight of the magnets was replaced with the rotor pole core, pole shoe, and field winding. For the purpose of calculating the axial deflection due to gravity, the weight acting on the rotor cylinder [36] is calculated as:

$$
\begin{gathered}
W_{\text {rotor-PMSG }}=\frac{g \sin \varphi}{N_{r}}\left(\rho_{f e} \pi R l t+M_{P M}+2 \rho_{f e} \pi R l h_{y r}\right) \\
W_{\text {rotor-EESG }}=\frac{g \sin \varphi}{N_{r}}\left(\rho_{f e} \pi R l t+M_{F e r p}+2 \rho_{f e} \pi R l t+M_{C u r}\right)
\end{gathered}
$$

where $\varphi$ is the generator tilt angle (set at $90^{\circ}$ representing assembly , transportation and lifting operations) ${ }^{\text {with }}$ the mass of the permanent magnet, rotor pole, and field winding estimated using (3), (4), and (5):

$$
\begin{gathered}
M_{P M}=2 \pi\left(R l\left(\frac{b_{m}}{\tau_{p}}\right) h_{m} \rho_{P M}\right. \\
M_{F e r p}=2 N_{p} l \rho_{f e}\left(h_{p c} \cdot b_{p c}+b_{p} \cdot h_{p s}\right) \\
M_{C u r}=l_{\text {Cur }} \cdot A_{C u r} \cdot \rho_{C u}
\end{gathered}
$$

where $l$ and $l_{\text {cur }}$ represents the length of the pole core and the field winding respectively. References [17], [21] were used to estimate the total masses for the active and inactive material. For the purpose of calculations, the generators were assumed to be operating at ambient temperature, and adequate cooling was assumed so that the temperature rise is within the limits to not warrant an effort to model deflection due to thermal expansion. The main set of electromagnetic and structural design variables used in the optimization process, main constants, and constraints are listed in Table 1 and Table 2.

Table 1. Design Variables and Bounds

\begin{tabular}{|l|l|c|c|c|}
\hline \multicolumn{1}{|c|}{ Symbol } & \multicolumn{1}{|c|}{ Description } & $\begin{array}{c}\text { PMSG-A, } \\
\text { EESG-B, } \\
\text { PMSG-MS-C }\end{array}$ & $\begin{array}{c}\text { Lower } \\
\text { Bound }\end{array}$ & $\begin{array}{c}\text { Upper } \\
\text { Bound }\end{array}$ \\
\hline$N_{r}$ & Number of rotor arms & A,B,C & 5 & 15 \\
\hline$t_{r}$ & Thickness of rotor back iron (mm) & A,B,C & 120 & 150 \\
\hline$b_{r}$ & $\begin{array}{l}\text { Rotor circumferential arm dimension } \\
(\mathrm{mm})\end{array}$ & A,B,C & 500 & 1500 \\
\hline$d_{r}$ & Rotor axial arm dimension (mm) & A,B,C & 100 & 1500 \\
\hline$t_{w r}$ & Rotor arm wall thickness (mm) & A,B,C & 10 & 200 \\
\hline$N_{s}$ & Number of stator arms & A,B,C & 5 & 15 \\
\hline$b_{s}$ & $\begin{array}{l}\text { Stator circumferential arm dimension } \\
\text { (mm) }\end{array}$ & A,B,C & 120 & 150 \\
\hline$d_{s}$ & Stator axial arm dimension (mm) & A,B,C & 500 & 1500 \\
\hline$t_{w s}$ & Stator arm wall thickness (mm) & A,B,C & 100 & 500 \\
\hline$r_{s}$ & Air-gap radius (m) & A,B,C & 0.5 & 9 \\
\hline$l$ & Core length (m) & A,B,C & 0.5 & 2.5 \\
\hline$h_{s}$ & Slot height (mm) & A,B,C & 50 & 250 \\
\hline$\tau_{p}$ & Pole pitch (mm) & A,B,C & 100 & 200 \\
\hline$h_{m}$ & Magnet height (mm) & A,C & 5 & 100 \\
\hline$I_{f}$ & No-load magnetization current & B & 10 & 500 \\
\hline$N_{f}$ & Number of turns in rotor winding & B & 10 & 500 \\
\hline
\end{tabular}


To design the medium-speed PMSG, a gear ratio of 40:1 was chosen, based on [9], so that the rated generator speed was $384 \mathrm{rpm}$. The torque specification for a medium-speed machine demands a smaller air-gap volume requirement. The main variables and constraints are consistent with the PMSG-DD design, but the output voltage requirement is relaxed to $15 \mathrm{kV}$.

Table 2. Constraints for Direct-Drive Designs

\begin{tabular}{|c|c|c|}
\hline Item & Description & $\mathrm{A}, \mathrm{B}, \mathrm{C}$ \\
\hline $1 / \mathrm{D}$ & Length-diameter ratio & $0.2<1 / \mathrm{D}<0.27$ \\
\hline$R^{2} l$ & Shear stress constraint & $>\frac{T}{2 \pi \sigma}$ \\
\hline$E_{p}(V)$ & Generator output phase voltage & $\begin{array}{c}500<E_{p}<5000 \quad[\mathrm{~A}, \mathrm{~B}] \\
500<E_{p}<15000[\mathrm{C}]\end{array}$ \\
\hline$f(H z)$ & Generator output frequency & $10<f<60$ \\
\hline$\widehat{B}_{g}(T)$ & Peak air-gap flux density & $0.7<B_{g}<1.2$ \\
\hline$\widehat{B}_{s y}(T)$ & Peak stator yoke flux density & $<2$ \\
\hline$\hat{B}_{s t}(T)$ & Peak stator tooth flux density & $<2$ \\
\hline$\widehat{B}_{r y}(T)$ & Peak rotor yoke flux density & $<2$ \\
\hline $\mathrm{A}_{1}(\mathrm{kA} / \mathrm{m})$ & Specific current loading & $<60$ \\
\hline $\mathrm{J}_{\mathrm{s}}\left(A / \mathrm{mm}^{2}\right)$ & Stator current density & $\mathrm{J}_{\mathrm{s}}<6$ \\
\hline$\eta(\%)$ & Generator efficiency & $\begin{array}{c}93<\eta<93.5[\mathrm{~A}, \mathrm{~B}] \\
93<\eta<96.5[\mathrm{C}]\end{array}$ \\
\hline$A_{\text {cus }}\left(\mathrm{mm}^{2}\right)$ & Stator conductor cross section & $A_{\text {cus }}>5$ \\
\hline$A_{\text {cur }}\left(\mathrm{mm}^{2}\right)$ & Rotor conductor cross section & $A_{\text {cur }}>10$ \\
\hline $\mathrm{J}_{\mathrm{r}}\left(A / \mathrm{mm}^{2}\right)$ & Rotor current density & $J_{r}<6$ \\
\hline$U_{a r}(\mathrm{~mm})$ & Rotor radial deflection & $<0.05 \mathrm{~g}$ \\
\hline$U_{a s}(\mathrm{~mm})$ & Stator radial deflection & $<0.05 \mathrm{~g}$ \\
\hline$Y_{a r}(\mathrm{~mm})$ & Rotor axial deflection & $<0.002 l$ \\
\hline$Y_{a s}(\mathrm{~mm})$ & Stator axial deflection & $<0.002 l$ \\
\hline$Z_{a r}(m m)$ & Rotor circumferential deflection & $<0.05 \pi \mathrm{R} / 360$ \\
\hline$Z_{a s}(\mathrm{~mm})$ & Stator circumferential deflection & $<0.05 \pi \mathrm{R}_{\text {st }} / 360$ \\
\hline$b_{s}(\mathrm{~mm})$ & Arm width constraint—stator & $b_{s}<\frac{2 \pi R_{o}}{n_{s}}$ \\
\hline$b_{r}(\mathrm{~mm})$ & Arm width constraint - rotor & $b_{r}<\frac{2 \pi R_{o}}{n_{r}}$ \\
\hline
\end{tabular}

\section{DFIG Design Optimization}

Induction generators are extremely popular in gear-driven wind turbines because they make it easier to connect high-speed machines to the electric grid. DFIGs are characterized by three-phase windings in both the armature and rotor. The stator slot and geometry are semienclosed. The rotor slots are also semienclosed with access to the rotor windings by means of a slip-ring assembly with brushes.

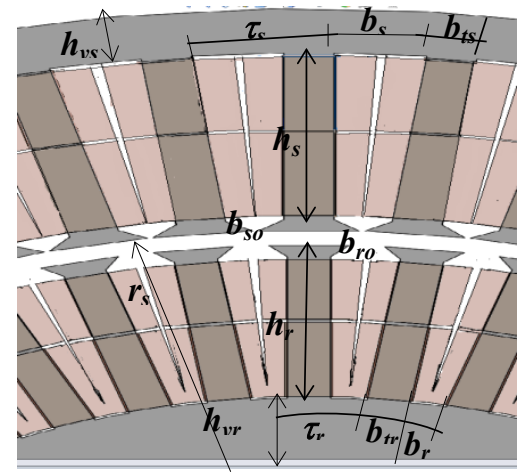

Figure 2. Basic design dimensions in a DFIG 
The main electromagnetic design dimensions of the DFIG are determined using the tangential stress design concept [43] with air-gap radius and machine length sufficient enough to produce the required torque. A two-layer winding was assumed for both the rotor as well as stator. The rated speed of the generator was assumed to be 1,200 rpm, which was used to optimize the operating slip. Because these machines are designed to operate at a high speed and low torque, the structural support requirements are not as demanding as those of the direct-drive generators. Nevertheless, an empirical estimate for structural mass was derived from a previous optimization study [21] that allowed extrapolating the relationships among generator active mass, inactive mass, and power rating, given by:

$$
M_{\text {Structure-DFIG }}=0.002 M_{\text {active }}^{2}+0.6457 M_{\text {active }}+645.24
$$

For the generator design, no mechanical losses were assumed from the gear train, and a three-stage epicyclic gearbox (ratio 125:1) was considered to step up the rotor speed to the rated generator speed. The gearbox was assumed to transmit only torque and no other rotor loads; hence, full mechanical power was assumed to be available at the output of the gearbox or the input to the generator. The main design variables and constraints used for iterating the designs are listed in Table 3 and Table 4. Table 5 lists the constants and material properties used for all the generator configurations.

Table 3. DFIG Design Variables

\begin{tabular}{|c|l|c|c|}
\hline Symbol & Description & Lower Bound & Upper Bound \\
\hline $\mathrm{R}(\mathrm{m})$ & Air-gap radius & 0.2 & 1 \\
\hline$L(m)$ & Stator length & 0.4 & 2 \\
\hline$h_{s}(m)$ & Stator slot height & 0.045 & 0.1 \\
\hline$h_{r}(m)$ & Rotor slot height & 0.045 & 0.1 \\
\hline$S_{N}$ & Optimal slip & -0.3 & -0.002 \\
\hline$h_{y s}(=$ & Yoke thickness & 0.04 & 0.15 \\
$\left.h_{y r}\right)(m)$ & & & \\
\hline$I_{\mu 0}(A)$ & No-load magnetization current & 5 & 200 \\
\hline$q_{1}$ & Stator slot/pole/phase & 5 & 8 \\
\hline
\end{tabular}

Table 4. Constraints Imposed for the DFIG Designs

\begin{tabular}{|c|c|}
\hline \multicolumn{1}{|l|}{ Item } & Constraint \\
\hline $1 / \mathrm{D}$ & $0.2<1 / \mathrm{D}<1.5$ \\
\hline$R^{2} l$ & $>\frac{T}{2 \pi \sigma}$ \\
\hline$E_{p}(\mathrm{~V})$ & $500<E_{p}<10000$ \\
\hline$f(H z)$ & $60<f<120$ \\
\hline$\hat{B}_{g}(T)$ & $0.7<B_{g}<1.2$ \\
\hline$\hat{B}_{s y}(T)$ & $<2$ \\
\hline$\hat{B}_{s t}(T)$ & $<2$ \\
\hline$\hat{B}_{r y}(T)$ & $<2$ \\
\hline $\mathrm{A}_{1}(\mathrm{kA} / \mathrm{m})$ & $<60$ \\
\hline $\mathrm{J}_{\mathrm{s}}\left(\mathrm{A} / \mathrm{mm}^{2}\right)$ & $<6$ \\
\hline$\eta(\%)$ & $>93$ \\
\hline$h_{s} / b_{s}$ & $4<h_{s} / b_{s}<10$ \\
\hline$I_{\mu 0} / I_{\text {srated }}$ & $0.3<I_{\mu 0} / I_{\text {srated }}<1.0$ \\
\hline
\end{tabular}

Table 5. Constants and Fixed Relations

\begin{tabular}{|l|l|l|}
\hline Symbol & Description & Value \\
\hline$\sigma_{P M}$ & Shear stress in PMSG & $40 \mathrm{kPa}$ \\
\hline$\sigma_{E E}$ & Shear stress in EESG & $48.37 \mathrm{kPa}$ \\
\hline$\sigma_{I G}$ & Shear stress in DFIG & $25 \mathrm{kPa}$ \\
\hline$g$ & Mechanical air gap & $0.002 \mathrm{R} \mathrm{mm}$ \\
\hline$R_{o}$ & Shaft radius & $0.524 \mathrm{~m}$ \\
\hline$\rho_{c u}$ & Density of copper & $8,900 \mathrm{~kg} / \mathrm{m}^{3}$ \\
\hline$\rho_{P M}$ & $\begin{array}{l}\text { Density of permanent } \\
\text { magnet }\end{array}$ & $7450 \mathrm{~kg} / \mathrm{m}^{3}$ \\
\hline$B_{r}$ & $\begin{array}{l}\text { Remnant flux density of } \\
\text { permanent magnet }\end{array}$ & $1.2 \mathrm{~T}$ \\
\hline$\rho_{f e}$ & Density of iron & $7,700 \mathrm{~kg} / \mathrm{m}^{3}$ \\
\hline$\rho_{s t e e l}$ & Density of structural steel & $7,850 \mathrm{~kg} / \mathrm{m}^{3}$ \\
\hline$C_{C u}$ & Unit cost of copper & $\$ 4.786 / \mathrm{kg}$ \\
\hline$C_{f e}$ & Unit cost of iron & $\$ 0.556 / \mathrm{kg}$ \\
\hline$C_{s t r u c}$ & Unit cost of structural steel & $\$ 0.501 / \mathrm{kg}$ \\
\hline$C_{P M}$ & $\begin{array}{l}\text { Unit cost of permanent } \\
\text { magnet }\end{array}$ & $\$ 95 / \mathrm{kg}$ \\
\hline
\end{tabular}




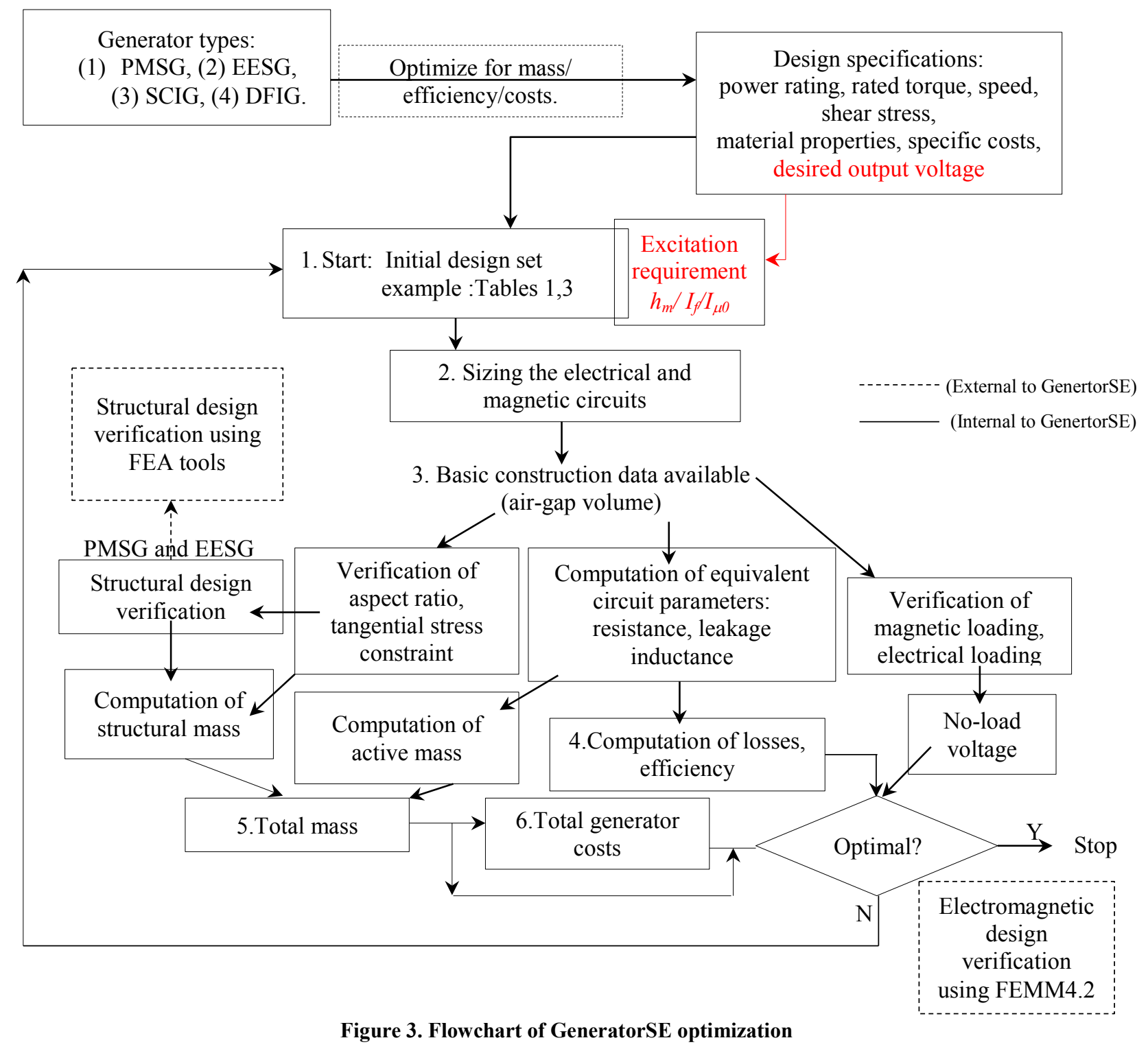

\section{Optimization in GeneratorSE and Comparison}

The optimization algorithm in GeneratorSE following the steps illustrated in Figure 3 involves simultaneous treatment of the multiple design problems - including structural design, magnetic design, and basic thermal design - to satisfy an objective function. Costs, mass, or efficiency can be independently optimized, and the solver computes the remaining two. A supplementary feature of GeneratorSE are the interfaces with FEMM4.2 [37] (an open-source finite-element program for solving low-frequency electromagnetic problems on two-dimensional planar and axisymmetric domains) and MATLAB, which allow the designer to verify the electromagnetic design. Starting with an initial set of variables, the designs are computed analytically and verified against predefined constraints to meet objective functions. The iteration is repeated until all the performance objectives are met and the final decision may be made based on the optimization method, which might require user involvement based on engineering knowledge. This might require re-initializing the variables (1) or (3) when the chosen construction data are altered according to an optimization method (deterministic or evolutionary). A cost optimization for the direct-drive generators was first carried out for three different efficiency bands: $91 \%-91.5 \%, 93 \%-93.5 \%$, and $94.5 \%-95 \%$. Figure 4 shows the Pareto front of the designs for the direct-drive configurations. 

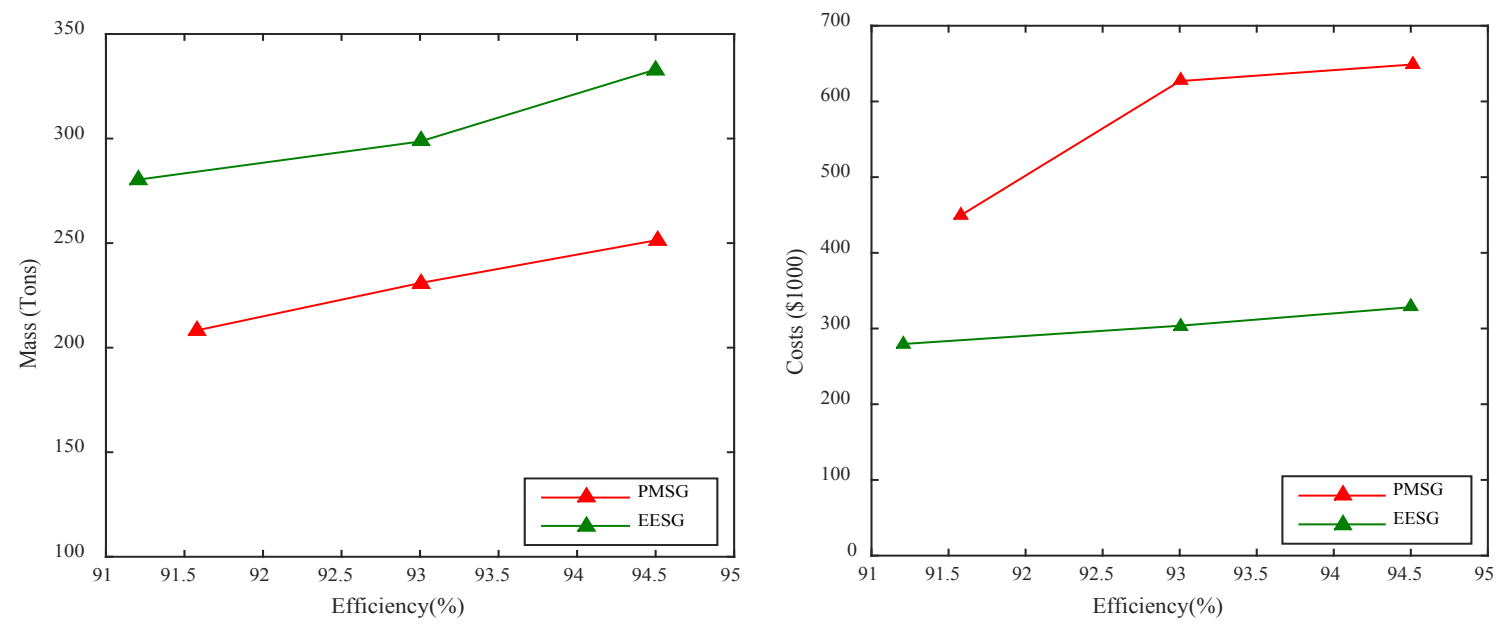

Figure 4. Pareto fronts of the cost-optimized designs

The objective function for cost optimization is:

$$
\text { val }_{T C}=M_{\text {act }} \cdot C_{\text {act }}+C_{\text {steel,struc }} \cdot M_{\text {steel,struc }}+C_{\text {mag,steel/iron }} \cdot M_{\text {mag,steel/iron }}
$$

where $M_{a c t}$ represents the electromagnetically active materials, including copper, magnetic steel/iron, and also magnets in the case of PMSG. $\mathrm{C}_{\text {act }}, \mathrm{C}_{\text {steel, struc, }}$, and $\mathrm{C}_{\mathrm{mag} \text {, steel/iron }}$ are specific costs for the respective construction materials. Preliminary results of the cost-optimized designs for the PMSG and EESG are shown inFigure 4. Note the nonlinearity in the costs of the PMSG, owing to the marginal increase in magnet requirement as the efficiency demand goes up. Table 6 presents the cost-optimized designs of the four machine types with the efficiency constrained to be more than $93 \%$. The PMSG-DD is at least 30\% lighter than the EESG at a comparable efficiency. For the support structure design studied in the present case, the PMSG presents the heaviest, followed by the EESG because it has the largest diameter. With a relatively higher peak air-gap flux density, back iron thickness is largest for the EESG. PMSG-MS proved to be most efficient and lightest design. 
Table 6. Optimized Generator Designs

\begin{tabular}{|c|c|c|c|c|}
\hline Parameters & PMSG-DD & EESG-DD & DFIG-HS & PMSG-MS \\
\hline Rated torque (MN-m) & 9.96 & 9.96 & 0.65 & 0.25 \\
\hline Gear ratio & 1 & 1 & $125: 1$ & $40: 1$ \\
\hline Rated speed (rpm) & 9.6 & 9.6 & 1,200 & 384 \\
\hline Optimized slip & - & - & -0.3 & - \\
\hline Air-gap radius (m) & 4.47 & 4.25 & 0.54 & 1.6 \\
\hline Core length $(\mathrm{m})$ & 2 & 1.93 & 1.53 & 0.7 \\
\hline Stator Slot height $(\mathrm{mm})$ & 57. & 66 & 77 & 84 \\
\hline Rotor slot height (mm) & - & - & 77 & - \\
\hline Pole pitch (mm) & 96 & 200 & 569 & 56 \\
\hline Pole pairs & 147 & 67 & 3 & 90 \\
\hline Rotor back iron thickness /yoke height (mm) & 83. & 210 & 69 & 75 \\
\hline Stator back iron thickness $(\mathrm{mm})$ & 88 & 210. & 69 & 80 \\
\hline Rotor axial arm dimension (mm) & 780 & 1,500 & - & 400 \\
\hline Rotor circumferential arm dimension $(\mathrm{mm})$ & 644.54 & 650 & - & 351 \\
\hline Rotor arm thickness (mm) & 200 & 61 & - & 61 \\
\hline Stator axial arm dimension $(\mathrm{mm})$ & 432 & 1,500 & - & 401 \\
\hline Stator circumferential arm dimension $(\mathrm{mm})$ & 580 & 652 & - & 352 \\
\hline Stator arm thickness $(\mathrm{mm})$ & 145 & 21 & - & 62 \\
\hline Air-gap flux density fundamental peak (T) & 0.79 & 1.06 & 0.717 & 1.07 \\
\hline No-load voltage (Vrms-phase) & 3,318 & 3,578 & 4,124 & 13,837 \\
\hline Magnet height (mm) & 14.9 & - & - & 13.36 \\
\hline No load magnetization current (A) & - & 76 & 54.37 & - \\
\hline Magnet $(\mathrm{t})$ & 4.96 & - & - & 0.6 \\
\hline Copper $(\mathrm{t})$ & 9 & 35 & 4 & 2 \\
\hline Iron $(\mathrm{t})$ & 54 & 115 & 10 & 12 \\
\hline Structural mass $(\mathrm{t})$ & 163 & 149 & 46 & 12 \\
\hline Total mass $(\mathrm{t})$ & 231 & 299 & 60 & 27 \\
\hline Efficiency (\%) & 93 & 93 & 96.27 & 96.5 \\
\hline Total material costs $(\$ 1,000)$ & 628 & 304 & 33 & 75 \\
\hline
\end{tabular}

Design validation: The electromagnetic design of the optimized generators was validated using two-dimensional finite-element analysis (FEA) in FEMM4.2 [37]. In each case, the optimized design dimensions from GeneratorSE were passed on to a MATLAB scripting interface that was used to automate the population of the two-dimensional geometries and perform a magnetostatic analysis to examine the magnetic loading at no load. Figure 5 shows the flux density contour plots for the PMSG-DD and EESG-DD. The spatial distribution of air-gap flux densities predicted by GeneratorSE compared to those predicted by FEMM4.2 for the direct-drive machines show very good correlation. Note that only the fundamental component of the stator slot harmonics (order represented by $\mu$ ) were included in the air-gap flux density predicted along the air-gap circumference by GeneratorSE given by (8) and (9):

$$
\begin{aligned}
\hat{B}_{\mathrm{g}}(\theta) & =\sum_{\mu .} K_{f v} B_{g} \cos \left(\frac{\pi}{\tau_{p}} \mu \theta\right) \\
K_{f v} & =\frac{4}{\pi} \sin \left(\frac{\pi b_{p}}{2 \tau_{p}} \mu\right)
\end{aligned}
$$



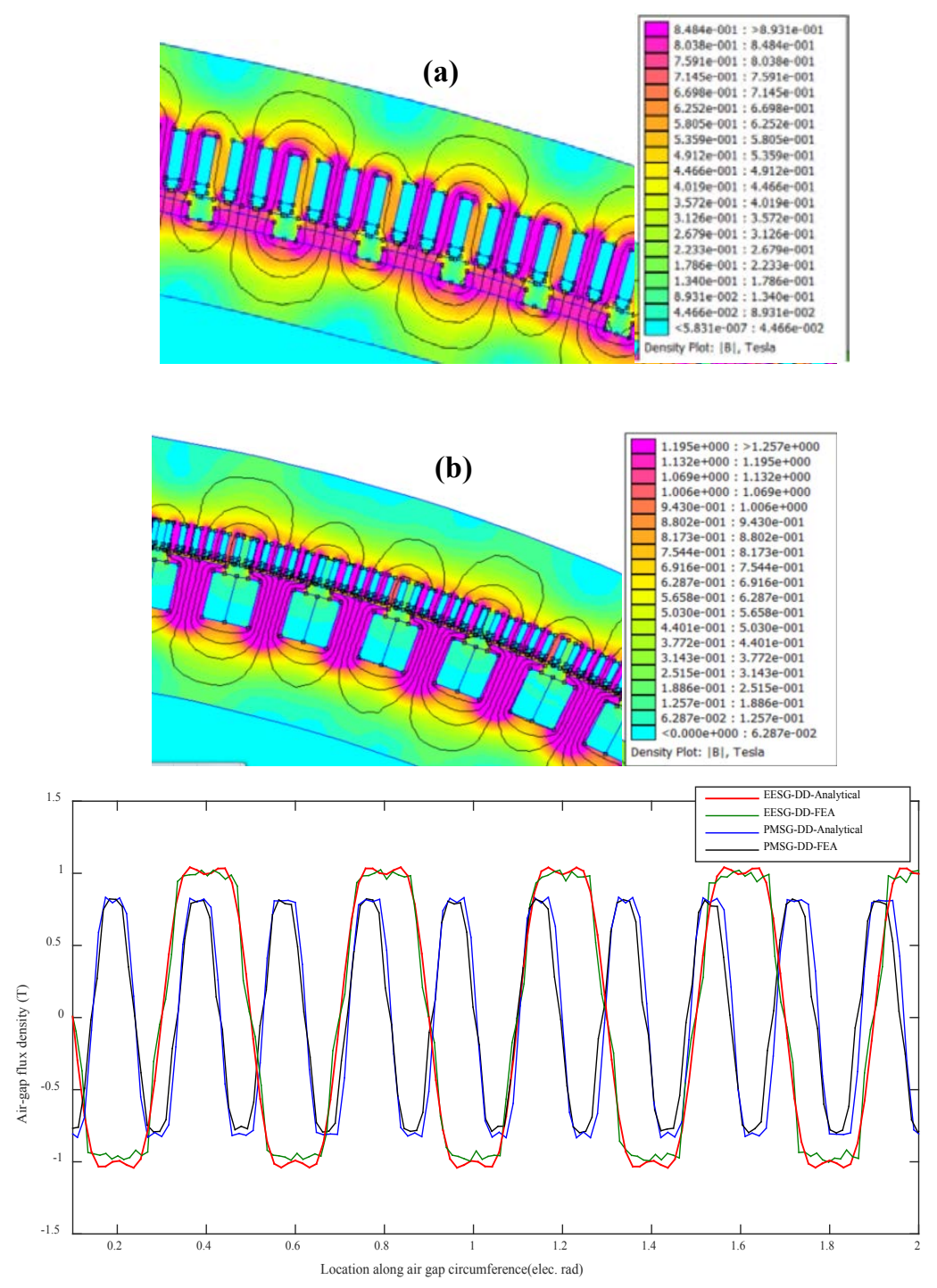

(c)

Figure 5. Flux contour plots: (a) PMSG-DD, (b) EESG-DD, and (c) comparison of air-gap flux densities

Static structural analysis was carried out to verify the deflections predicted by GeneratorSE. A comparison of the results for both machines is shown inTable 7. Figure 6 shows examples of the maximum values of the structural deflections computed in ANSYS, with a normal stress of $0.19 \mathrm{MPa}$, a tangential stress of $0.04 \mathrm{MPa}$ (along Y), and standard earth gravity (acting along Z - a condition representing lifting or transportation) considered for the PMSG. The corresponding values for the EESG were $0.57 \mathrm{MPa}$ and $48.3 \mathrm{MPa}$, respectively. The exercise was repeated for the EESG-DD, and the analytically computed deflections were found to be $83 \%-114 \%$ of FEA results. The greatest difference is observed in the axial component; it must be mentioned that the weight of windings and magnets were included as lumped load acting at the center of mass in the FEA model, but is expected to reduce by more accurate modeling of windings. 
Table 7. Comparison of Structural Deflections

\begin{tabular}{|l|c|c|c|c|c|c|c|c|}
\hline \multicolumn{1}{|c|}{ Parameter } & $\begin{array}{c}\text { GeneratorSE } \\
\text { Rotor }\end{array}$ & $\begin{array}{c}\text { FEA } \\
\text { Rotor }\end{array}$ & $\begin{array}{c}\text { GeneratorSE } \\
\text { Stator }\end{array}$ & $\begin{array}{c}\text { FEA } \\
\text { Stator }\end{array}$ & $\begin{array}{c}\text { GeneratorS } \\
\text { E Rotor }\end{array}$ & $\begin{array}{c}\text { FEA } \\
\text { Rotor }\end{array}$ & $\begin{array}{c}\text { GeneratorSE } \\
\text { Stator }\end{array}$ & $\begin{array}{c}\text { FEA } \\
\text { Stator }\end{array}$ \\
\hline & \multicolumn{7}{|c|}{ PMSG } \\
\hline $\begin{array}{l}\text { Radial } \\
\text { deflection (mm) }\end{array}$ & 0.43 & 0.45 & 0.43 & 0.435 & 0.42 & 0.403 & 0.442 & 0.422 \\
\hline $\begin{array}{l}\text { Circumferential } \\
\text { deflection (mm) }\end{array}$ & 3.88 & 3.93 & 3.95 & 4.31 & 2.88 & 2.507 & 3.96 & 4.03 \\
\hline $\begin{array}{l}\text { Axial deflection } \\
\text { (mm) }\end{array}$ & 0.45 & 0.54 & 1.646 & 1.727 & 0.15 & 0.198 & 0.379 & 0.41 \\
\hline
\end{tabular}
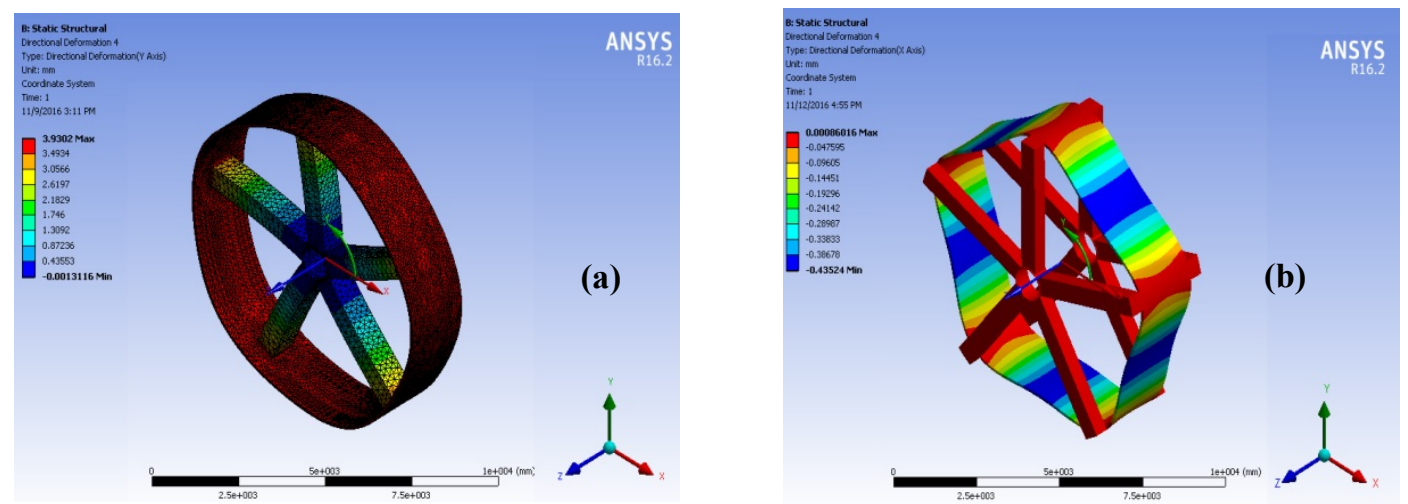

Figure 6. Structural deflections computed in ANSYS for the PMSG: (a) circumferential deflection in rotor, (b) radial deflection in stator
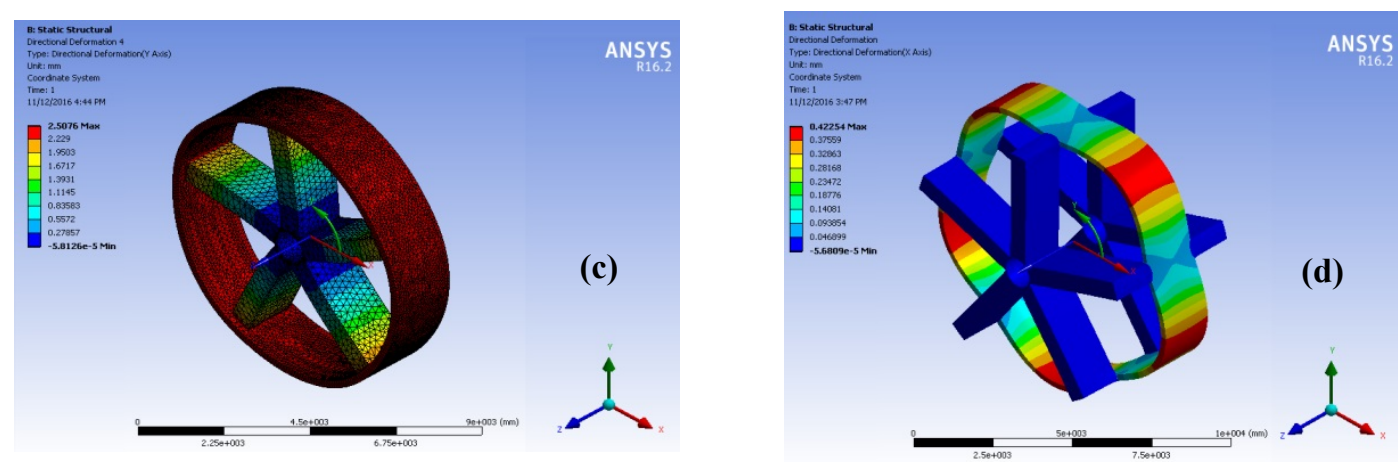

Figure 7. Structural deflections computed in ANSYS for the EESG: (a) circumferential deflection in rotor, (b) radial deflection in stator

\section{LCOE Analysis for the Optimized Generator Designs}

A simplified analysis was performed to determine the LCOE for each of the generator technologies applied to the DTU turbine, henceforth referred to as DTU_PMSG-DD, DTU_EESG-DD, DTU_PMSG-MS, and DTU_DFIG. The goal was to show a preliminary comparison of the impact of different generator topologies for very large-scale offshore wind turbines from a full system LCOE perspective. In the case of the direct-drive DTU turbine, the output from the generators was assumed to be processed and coupled to the electric grid through a fully rated power electronic converter system. In the cases of the DTU_PMSG-MS and DFIG_DTU, a single-stage gearbox and a three-stage gearbox were assumed to drive the medium-speed PMSG and the high-speed wound-rotor induction generator, respectively. The rotor power from the DFIG was processed and coupled to the grid by a partial-rated power electronic converter. Five hundred units of each type of turbine were assumed to be installed onto monopile foundations located at a site approximately $42 \mathrm{~km}$ from shore at the eastern edge of Dominion's commercial 
Virginia offshore lease for a total capacity factor of approximately 39\% [47]. The main specifications for the DTU 10-MW reference turbine are listed in Table 8. The integrated rotor power as a function of wind speed is also shown.

Table 8. Key Specifications of the DTU 10-MW Reference Turbine [5]

\begin{tabular}{|l|l|}
\hline Parameter & Value \\
\hline Wind regime & IEC Class 1A \\
\hline Rotor orientation & Clockwise rotation-upwind \\
\hline Control & Variable speed, collective pitch \\
\hline Cut-in/cut-out wind speed & $4 \mathrm{~m} / \mathrm{s} / ; 25 \mathrm{~m} / \mathrm{s}$ \\
\hline Rated wind speed & $11.4 \mathrm{~m} / \mathrm{s}$ \\
\hline Rotor diameter & $178.3 \mathrm{~m}$ \\
\hline Hub diameter & $5.6 \mathrm{~m}$ \\
\hline Maximum rotor speed & $9.6 \mathrm{rpm}$ \\
\hline Rated torque & $9.94 \mathrm{MNm}$ \\
\hline Rotor mass & $227,962 \mathrm{~kg}$ \\
\hline
\end{tabular}

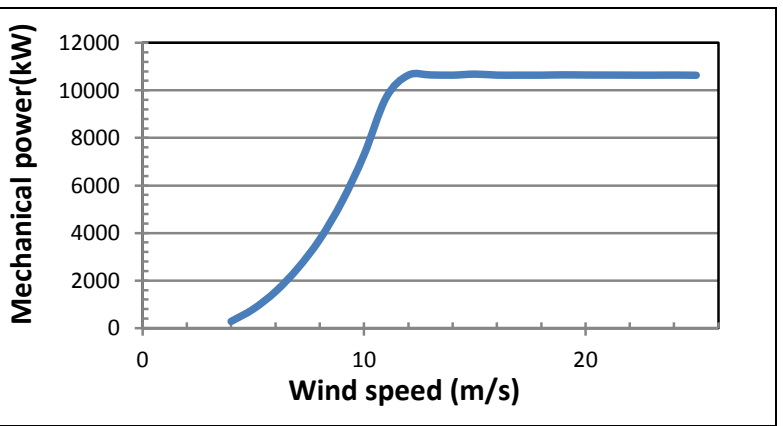

As the first step, the basic design dimensions, costs, and efficiency for the four generator configurations from GeneratorSE were passed on to NREL's Wind Turbine Design Cost and Scaling Model [40], which was used to determine the costs for the rest of the drivetrain elements for the direct-drive system and to estimate the turbine capital cost. In the cases of the DTU_DFIG and DTU_PMSG_MS, NREL's DriveSE [39] was used to size and cost the other major load-bearing components, including the low-speed shaft, main bearing(s), gearbox, and bedplate. The generator efficiency from GeneratorSE together with other drivetrain mechanical losses, if any were used to develop unique power curves for each of the generator technologies which were fed into AWS Truepower's Openwind [48] along with the DTU turbine specifications to estimate the annual energy production (AEP). The assumptions about generator reliability were used to develop inputs to ECN's O\&M Tool v4.4 [49], which estimates O\&M expense. The resulting O\&M, turbine capital cost, and AEP values were fed into NREL's Offshore Balanceof-System (BOS) Model [50] to calculate the BOS costs and overall LCOE. Figure 8 illustrates the data flow and tools used in the study.

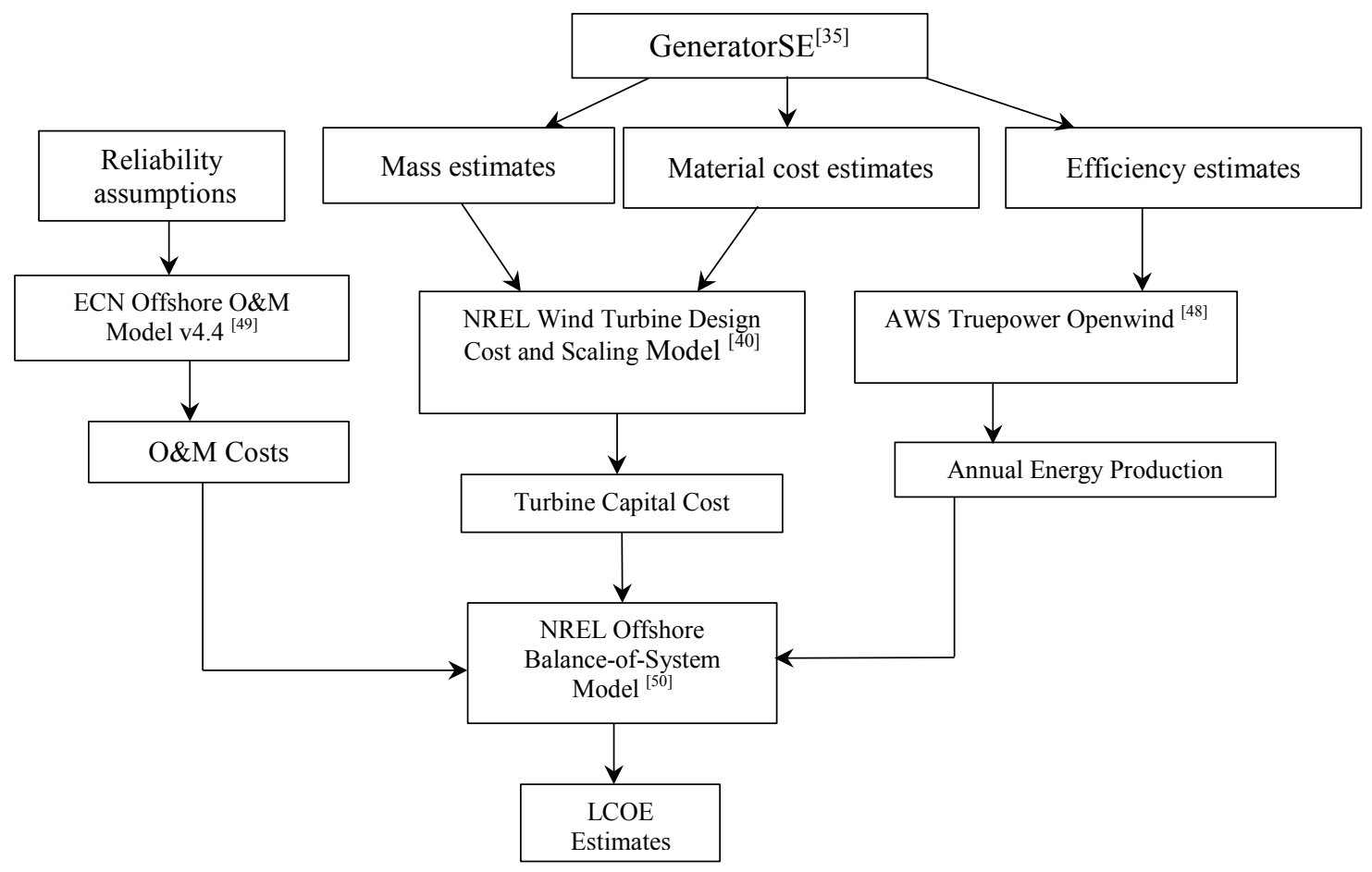

Figure 8. Techno-economic assessment for the three generator configurations 
The LCOE analysis for this study did not consider policy incentives, the impacts of underlying economic conditions or the costs of building new transmission lines. The standard annual technology baseline (ATB) LCOE equation is given here:

$$
L C O E=\frac{(\operatorname{Cap} E x \cdot F C R)+O p E x}{A E P_{n e t} \cdot\left(\frac{1}{1000}\right)}
$$

where CapEx is capital expenditures ( $\$ \mathrm{US} / \mathrm{kW}), \mathrm{AEP}_{\text {net }}$ is the net average annual energy production (MWh/ $\mathrm{MW} / \mathrm{yr}$ ), and OpEx refers to operational expenditures ( $\$ \mathrm{US} / \mathrm{kW} / \mathrm{yr})$. The fixed charge rate $(\mathrm{FCR})$ represents the amount of revenue required to pay the carrying charges ${ }^{3}$ as applied to the CapEx on that investment during the expected project life on an annual basis. ${ }^{4}$ FCR can be calculated using the equation:

$$
F C R=\frac{d(1+d)^{n}}{(1+d)^{n}-1} \cdot \frac{1-(T \cdot P V d e p)}{(1-T)}
$$

Based on [51], an FCR of $10.8 \%$ was used for the present study considering the economic life at 20 years; discount rate, $d$, at $7 \%$; an effective tax rate, $T$, of $40 \%$; and $78 \%$ for PVdep using the Modified Accelerated Cost Recovery System(MACRS) The costs were developed using U.S. dollars for the year 2016. To calculate an LCOE for each technology, a baseline wind power plant was modeled using the following assumptions:

- The wind turbine for each technology was based on the DTU 10-MW platform with adjustments made to the power curve for each generator scenario.

- The site characteristics and turbine array layout were held constant for each scenario.

- Turbine efficiency was held constant at $93 \%$ for direct-drive turbines. For DTU_DFIG and DTU_PMSG_MS turbines, drivetrain mechanical losses were assumed to be 3.5\%.

The parameters for the baseline wind power plant are tabulated inTable 9.

Table 9. Baseline Wind Power Plant Parameters

\begin{tabular}{|l|l|l|}
\hline Description & Units & Value \\
\hline Number of turbines & {$[\#]$} & 50 \\
\hline Turbine rating & {$[\mathrm{MW}]$} & 10 \\
\hline Rotor diameter & {$[\mathrm{m}]$} & 178.3 \\
\hline Hub height & {$[\mathrm{m}]$} & 119 \\
\hline Water depth & {$[\mathrm{m}]$} & 28.5 \\
\hline Distance to export cable landfall & {$[\mathrm{km}]$} & 46 \\
\hline Distance to installation port & {$[\mathrm{km}]$} & 77.75 \\
\hline
\end{tabular}

For each of the generator scenarios, turbine capital cost needed to be estimated. This began by estimating the material cost of the generator using the GeneratorSE model based on material pricing sourced from [44]-[46]. A cost factor, $K_{\mathrm{f}}$, to estimate the factory gate pricing of the generator was developed through a simple regression from [21], which presented cost breakdowns for 0.75-MW, 1.5-MW, 3-MW, 5-MW, and 10-MW PMSG-DD and EESG generators. The resulting total cost factor for the DTU_PMSG-DD and DTU_PMSG-MS was 1.79, and for the DTU_WWSG-DD and DTU_DIFG the resulting cost factor was 1.61. So, for example, the total cost of the generator for the DTU_PMSG-DD was 1.79x (material cost). Similar results were reported in [52] for the PMSG machines. Generator costs are given inTable 10. Note that the direct-drive machines cost significantly more than the DFIG machine, which results from the additional amount of material needed to manufacture it. Also the

${ }^{3}$ Carrying charges include the return on debt, return on equity, taxes, and depreciation.

${ }^{4}$ The FCR does not allow for detailed analysis of specific financing structures; however, these structures can be represented through the use of a weighted average cost of capital as the discount rate input. 
DTU_PMSG-DD costs significantly more than the DTU_EESG-DD because of the high cost of neodymium magnets.

Table 10. Estimated Generator Costs by Technology Type

\begin{tabular}{|l|c|c|c|c|}
\hline & DTU_PMSG-DD & DTU_EESG-DD & DTU_PMSG-MS & DTU_DFIG \\
\hline $\begin{array}{l}\text { Generator Cost } \\
(\$ 1,000 \text { 's USD) }\end{array}$ & 1,120 & 490 & 24 & 73 \\
\hline
\end{tabular}

The estimated generator cost was then used to develop a turbine capital cost. The balance of the turbine costs were estimated via NREL's Wind Turbine Design Cost and Scaling Model [40]. The DTU 10-MW parameters from Table 8 were used as model inputs, and the modeled cost results for each of the turbines are given in Table 11.

Table 11. Turbine Capital Cost Breakdown by Generator Type

\begin{tabular}{|l|c|c|c|c|}
\hline Turbine Breakdown & $\begin{array}{c}\text { DTU_PMSG_DD } \\
(\$ / \mathrm{kW})\end{array}$ & $\begin{array}{c}\text { DTU_EESG_DD } \\
(\$ / \mathrm{kW})\end{array}$ & $\begin{array}{c}\text { DTU_PMSG_MS } \\
(\$ \mathbf{k W})\end{array}$ & $\begin{array}{c}\text { DTU_DFIG } \\
(\$ / \mathrm{kW})\end{array}$ \\
\hline Blades (3) & 91.4 & 91.4 & 91.4 & 91.4 \\
\hline $\begin{array}{l}\text { Hub nose } \\
\text { cone/spinner) }\end{array}$ & 45.7 & 45.7 & 45.7 & 45.7 \\
\hline Pitch mechanism and bearings & 40.3 & 40.3 & 40.3 & 40.3 \\
\hline Bearings & 34.3 & 34.3 & 34.3 & 34.3 \\
\hline Spinner, nose cone & 2.9 & 2.9 & 2.9 & 2.9 \\
\hline $\begin{array}{l}\text { e.g., mechanical brake, high- } \\
\text { speed coupling }\end{array}$ & 2.8 & 2.8 & 4.8 & 4.8 \\
\hline Generator & 111.9 & 49.0 & 2.3 & 7.3 \\
\hline Gearbox & - & - & 147.7 & 165.1 \\
\hline Main shaft & 148.5 & 148.5 & 47.7 & 47.7 \\
\hline Variable-speed electronics & 213.7 & 213.7 & 213.7 & 213.7 \\
\hline Yaw drive and bearing & 22.5 & 22.5 & 22.5 & 22.5 \\
\hline Main frame & 118.8 & 118.8 & 118.8 & 118.8 \\
\hline Electrical connections & 75.9 & 75.9 & 75.9 & 75.9 \\
\hline Hydraulic, cooling system & 31.3 & 31.3 & 31.3 & 31.3 \\
\hline Nacelle cover & 6.3 & 6.3 & 6.3 & 6.3 \\
\hline $\begin{array}{l}\text { Control, safety system, and } \\
\text { condition monitoring }\end{array}$ & 11.2 & 11.2 & 11.2 & 11.2 \\
\hline Misc. & 10.0 & 10.0 & 10.0 & 10.0 \\
\hline Rotor/nacelle assembly total & $\mathbf{1 , 0 6 4 . 4}$ & $\mathbf{9 9 5 . 1}$ & $\mathbf{9 9 7 . 5}$ & $\mathbf{1 , 0 2 2 . 2}$ \\
\hline Tower & $\mathbf{1 9 0 . 6}$ & $\mathbf{2 0 0 . 7}$ & $\mathbf{1 7 9 . 7}$ & $\mathbf{1 7 9 . 7}$ \\
\hline Total & $\mathbf{1 , 2 5 5 . 0}$ & $\mathbf{1 , 1 9 6}$ & $\mathbf{1 1 7 7}$ & $\mathbf{1 , 2 0 2}$ \\
\hline
\end{tabular}

The AEP was estimated by first creating a power curve for the 10-MW machine by applying the generator and drivetrain efficiencies to the mechanical power generated by the turbine (Table 8). The resulting power curves were then used to estimate the AEP using AWS Truepower's Openwind, with the weather data taken from the Virginia wind energy area [47]. To calculate the O\&M expenses, ECN's O\&M Tool v4.4 [49] was used, which required annual failures and a distribution of the type of failure based on repair requirements (e.g., small repair, preventative repair, major repair). Reference [8], [31], and [53] were used to derive the failure rate distribution for the four generator typeswhich are listed in Table 12. Note that failure rate distributions for the EESG and DFIG are based on designs with slip-ring assemblies. 
Table 12. O\&M Failure Rates and Repair Type Distributions

\begin{tabular}{|l|c|c|c|c|c|}
\hline & DTU_PMDD_DD & $\begin{array}{c}\text { DTU_EESG- } \\
\text { DD }\end{array}$ & DTU_PMSG-MS & DTU_DFIG & Units \\
\hline $\begin{array}{l}\text { Generator } \\
\text { failures }\end{array}$ & 0.076 & 0.245 & 0.218 & 0.123 & Failures/year \\
\hline Small repair & 97 & 74 & 93 & 74 & $\%$ \\
\hline Major repair & 2 & 24 & 5 & 24 & $\%$ \\
\hline $\begin{array}{l}\text { Major } \\
\text { replacement }\end{array}$ & 1 & 2 & 2 & 2 & $\%$ \\
\hline Total O\&M cost & 62.59 & 64.24 & 62.99 & 63.17 & $\$ / \mathrm{kW}$ \\
\hline
\end{tabular}

The BOS cost—which encompasses all costs for the wind power plant excluding turbine capital cost, O\&M cost, and financial costs - was estimated using NREL's Offshore BOS Model [50]. The parameters shown in Table 9 were used to model the wind power plant, and the turbine characteristics varied slightly from one design to another. The rotor/nacelle assembly mass was heavier for the DTU_EESG-DD design, and the model accounts for this when provided a user-defined input. The Offshore BOS Model also calculates LCOE using the standard annual technology baseline equation and the assumptions given at the beginning of this section. Results of the LCOE analysis are summarized inTable 13.

Table 13. LCOE Analysis Results Summary

\begin{tabular}{|l|c|c|c|c|}
\hline LCOE Results & DTU_PMSG-DD & DTU_EESG-DD & DTU_PMSG-MS & DTU_DFIG \\
\hline $\begin{array}{l}\text { Turbine CapEx } \\
(\$ / \mathrm{kW})\end{array}$ & 1,255 & 1,196 & 1,179 & 1,202 \\
\hline O\&M cost $(\$ / \mathrm{kW})$ & 62.6 & 64.2 & 63.0 & 63.2 \\
\hline BOS costs $(\$ / \mathrm{kW})$ & 1,640 & 1,639 & 1,639 & 1,640 \\
\hline AEP $($ net $\mathrm{GWh} / \mathrm{yr})$ & 1,662 & 1,661 & 1,662 & 1,653 \\
\hline LCOE $(\$ / \mathrm{MWh})$ & 127.7 & 126.8 & 124.9 & 126.6 \\
\hline
\end{tabular}

The AEP numbers in the present study were similar across all models so that drivetrain efficiency was not the major economic driver. This was achieved by assuming no mechanical losses in the drivetrain for the direct-drive systems and $3.5 \%$ for the geared systems. In summary, the results suggest that that the lowest LCOE potentials for the DTU 10-MW turbine are possible with the PMSG_MS concept, as was also predicted by the INNWIND study [9]. Nevertheless, the advantage presented by NREL's GeneratorSE is a more realistic estimate for mass and material costs, the opportunity to examine the design sensitivities to different materials or material prices and assess potential of new adaptations to the standard generator topologies investigated above. For example, any variability in magnet prices or solutions to address reliability issues can be implemented to examine their competitiveness. For the directdrive generators the costs of magnets and reliability issues with brushes are the biggest deterrents. New innovations may allow both EESG_DD and PMSG_DD concepts to become more cost competitive if their capital costs can be lowered without sacrificing performance in reliability. It must be noted that this LCOE analysis was performed to highlight a potential case in which GeneratorSE can provide solid metrics to inform analysis. Because of large variability in project parameters and site-specific elements, these results should be taken as representative only.

\section{Conclusion}

This paper presented cost-optimized generator designs for the DTU 10-MW reference turbine using NREL's newly developed systems engineering tool GeneratorSE. The optimization structure and attributes were briefly outlined to demonstrate the opportunities that users can take advantage of when realizing a generator considering electromagnetic, structural, and basic thermal design. A permanent-magnet synchronous machine, an electrically excited synchronous machine, a medium-speed PMSG, and a high-speed DFIG were designed. A 500-MW offshore wind power plant located off the coast of Virginia with 50 of the DTU turbines of each generator technology type were separately evaluated for their LCOE potential. 
Among the competing direct-drive systems, the change in LCOE is small, primarily because of the dilution of the cost benefits by the large amount of other costs that are included in the LCOE calculation. In particular, offshore systems are dominated by BOS costs and OpEx. Although generator design influences these costs, the analysis here did not show strong differences between the designs. The analysis supported earlier studies that found mediumspeed PMSG design to be the most promising candidate at the 10-MW level because the design uses significantly less permanent-magnet material than its direct-drive counterpart while sustaining decent reliability levels even with the inclusion of a gearbox (such that OpEx is relatively low compared with the other designs). The high cost of magnets remains a major deterrent for the direct-drive PMSG, yet adjustments to price sensitivity can change this outlook. If costs for permanent magnets fall significantly, the high reliability of the PMSG and low OpEx combined with lower CapEx would make it a very competitive option. The EESG and DFIG systems are both disadvantaged because of the reliability impacts in particular of maintenance of the brushes for the field excitation systems. This indicates that innovations targeting the reliability and design of the field excitation systems for these machines may hold promise for making them more competitive options for very large-scale offshore wind turbine applications.

\section{Acknowledgments}

This work was supported by the U.S. Department of Energy (DOE) under Contract No. DE-AC36-08GO28308 with the National Renewable Energy Laboratory. Funding for the work was provided by the DOE Office of Energy Efficiency and Renewable Energy, Wind and Water Power Technologies Office.

The U.S. Government retains and the publisher, by accepting the article for publication, acknowledges that the U.S. Government retains a nonexclusive, paid-up, irrevocable, worldwide license to publish or reproduce the published form of this work, or allow others to do so, for U.S. Government purposes.

\section{References}

${ }^{1}$ Sieros, G., Chaviaropoulos, P., Sorensen, J. D., Bulder, B. H., and Jamieson, P., "Upscaling Wind Turbines: Theoretical and Practical Aspects and Their Impact on the Cost of Energy," Wind Energy, Vol. 15, No. 1, 2012, pp. 3-17.

2 “The World's 10 Biggest Wind Turbines," URL: http://www.power-technology.com/features/featurethe-worlds-biggest-windturbines-4154395/ [cited 10 November 2016].

${ }^{3}$ Hofmann, M., and Sperstad, I. B., "Will 10 MW Wind Turbines Bring Down the Operation and Maintenance Cost of Offshore Wind Farms?”, Energy Procedia, Vol. 53, 2014, pp. 231- 238.

4 "Design of State of the Art 10-20 MW Offshore Wind Turbines," URL: http://www.innwind.eu/ [cited 10 November 2016].

${ }^{5}$ Mcdonald, A. S., and Keysan, O, "How Electrical Machine and Drivetrain Design Can Influence Offshore Wind Cost of Energy," Electromagnetics in Renewable Energy Generation, 8th July, 2015, Edinburgh University.

${ }^{6}$ Bak, C., Zahle, F., Bitsche, R., Kim, T., Yde, A., Henriksen, L. C., Natarajan, A., and Hansen, M., "DTU 10-MW Reference Wind Turbine, DTU Wind Energy Report-I-0092, Kongens Lyngby, Denmark, June 2013.

${ }^{7}$ Hansen, L. H., Helle, L., Blaabjerg, F., Ritchie, E., Munk-Nielsen, S., Bindner, H., Sørensen, P., and Bak-Jensen, B., "Conceptual Survey of Generators and Power Electronics for Wind Turbines," Riso Nat. Lab. Tech. Rep. Riso-R-1205(EN), Roskilde, Denmark, Dec. 2001.

${ }^{8}$ Carroll1, J., McDonald, A., Dinwoodie, I., McMillan, D., Revie, M., and Lazakis, I., "Availability, Operation and Maintenance Costs of Offshore Wind Turbines with Different Drive Train Configurations," Wind Energy, doi: 10.1002/we.2011.

9 "PI-Based Assessment of Innovative Concepts," INNWIND.EU Deliverable 1.23, Roskilde, Denmark, URL: http://www.innwind.eu/Publications/Deliverable-reports [cited 10 November 2016].

${ }^{10}$ Fingersh, L., Hand,M. and Laxson,A., "Wind Turbine Design Cost and Scaling Model”, Technical Report NREL/TP-50040566, December 2006.

11 McDonald, A. S, Mueller, M. A., and Polinder, H., "Structural Mass in Direct-Drive Permanent Magnet Electrical Generators," IET Renewable Power Generation, Vol. 2, No. 1, pp. 3-15.

12 Shrestha, G., Polinder, H., and Ferreira, J. A., "Scaling Laws for Direct Drive Generators in Wind Turbines," Proceedings of IEMDC, 3-6 May 2009, pp. 797-803. 
13 “XD115-5MW,” URL: http://www.darwind.nl/Wind-turbines/XD115-5MW [cited 10 November 2016].

14 Stiedel, H., "Permanent Magnet Generators for Wind Turbines Status and Outlook," URL: http://www.coilwindingexpo.com/berlin/ files/permanent magnet generators for wind turbines henrik stiesdal.pdf [cited 10 November 2016].

15 URL: https://www.gerenewableenergy.com/content/dam/gepower-renewables/global/en US/documents/haliade-offshorewind-turbine.pdf [cited 10 November 2016].

16 Keysan, O., "Superconducting Generators for Large Offshore Wind Turbines," Ph.D. Thesis, University of Edinburgh, Edinburgh, United Kingdom, 2014.

17 Li, H., and Chen, Z., "Design Optimization and Comparison of Large Direct-Drive Permanent Magnet Wind Generator Systems," Proceedings of International Conference on Electrical Machines and Systems 8-11 Oct. 2007, Seoul, Korea.

18 Li, H., Chen, Z., and Polinder, H., "Optimization of Multibrid Permanent-Magnet Wind Generator Systems," IEEE Transactions on Energy Conversion, Vol. 24, No. 1, March 2009, pp. 82-92. doi: 10.1109/TEC.2008.2005279.

19 Dubois, M. R., “Optimized Permanent Magnet Generator Topologies for Direct-Drive Wind Turbines," Ph.D. dissertation, Delft Univ. Technol., Delft, The Netherlands, 2004.

20 Grauers, A., "Design of direct-driven permanent-magnet generators for wind turbines," Ph.D. Dissertation, Chalmers Univ. Technol., Goteborg, Sweden, 1996.

21 Li, H. Chen, Z., and Polinder, H., Research Report on numerical evaluation of various variable speed wind generator systems, UpWind Deliverable No: D 1B2.b.3, 2006.

22 Polinder, H., “Design Optimization of a Synchronous Generator for a Direct-Drive Wind Turbine,” July 2001.

23 Polinder, H., van der Pijl, F. F. A., de Vilder, G., and Tavner, J. "Comparison of Direct-Drive and Geared Generator Concepts for Wind Turbines," IEEE Transactions on Energy Conversion, Vol. 21, No. 3, September 2006.

24 Zhang, Z., Matveev, A., Øvrebø, S., Nilssen, R., and Nysveen, A., "State of the Art in Generator Technology for Offshore Wind Energy Conversion Systems," 2011 IEEE International Electric Machines \& Drives Conference (IEMDC), Niagara Falls, ON,pp.1131-1136. Doi: 10.1109/IEMDC.2011.5994760.

25 Polinder, H., Bang, D., Rpjom,V. R., McDonald, A. S., and Mueller, M. A, "10MW Wind Turbine Direct-Drive Generator Design with Pitch or Active Speed Stall Control,” Proceedings of IEMDC, 3-5 May 2007, pp. 1390-1395.

26 Zhang, Z., Chenb, A., Matveev, A., Nilssen, R., and Nysveen, A., "High-Power Generators for Offshore Wind Turbines," doi: 10.1016/j.egypro.2013.07.158.

27 Yuanyuan, X., Maki, N., and Izumi, M., "Performance Comparison of 10-MW Wind Turbine Generators With HTS, Copper, and PM Excitation," IEEE Transactions on Applied Superconductivity, Vol. 25, No. 6, 2015, http://ieeexplore.ieee.org/stamp/stamp.jsp?arnumber=7312921.

28 Liseth, H. E., and Nilssen, R., "10 MW Reference Wind Turbine,” Department of Electric Power Engineering, Norwegian University of Science and Technology, Trondheim, Norway,2011.

29 Stuebig, C., Seibel, A., Schleicher, K., Haberjan, L., Kloepzig, M., and Ponick, B., "Electromagnetic Design of a 10 MW Permanent Magnet Synchronous Generator for Wind Turbine Application," 2015 IEEE International Electric Machines \& Drives Conference (IEMDC), Coeur d'Alene, $\quad$ ID, $\quad$ pp. Doi: 10.1109/IEMDC.2015.7409214.

30 Bradley, S., "Floating Wind Foundations and Turbine Topology, Offshore Wind Structures Conference, London, URL: http://www.eti.co.uk/wp-content/uploads/2015/04/Floating-Wind-Foundations-and-Turbine-Topology-V1 2-UPDATEDCOMMS.pdf [cited 10 November 2016].

31 Caroll, J., McDonald, A., Feuchtwang, J., and McMillan, D., "Drivetrain Availability in Offshore Wind Turbines," EWEA 2014, 10-13 March 2014, Barcelona, Spain. 
32 URL: http://www.tki-windopzee.n1/files/2015-09/20150911-rap-offshore.wind.turbine. development.the. nether lands-dnvglf.pdf [cited 10 November 2016].

33 Kosowatz, J., "Offshore Market Sprouts Larger Wind Turbines,” August 2014, URL: https://www.asme.org/engineeringtopics/articles/renewable-energy/offshore-market-sprouts-larger-wind-turbines [cited 10 November 2016].

34 "8 MW Platform," URL: http://www.adwenoffshore.com/products-services/products/8-mw-turbines// [cited 10 November 2016].

35 Sethuraman, L, and Dykes, K., "Generator SE, A Sizing Tool for Variable Speed Wind Turbine Generators," NREL Technical Report, forthcoming.

36 McDonald, A. S., "Structural Analysis of Low Speed, High Torque Electrical Generators for Direct Drive Renewable Energy Converters," Ph.D. Thesis, University of Edinburgh, Edinburgh, United Kingdom, 2008.

37 Meeker, D., Finite Element Method Magnetics: Version 4.2-User's Manual, URL: http://www.femm.info/wiki/Documentation/. [Cited 10 November 2016].

38 URL: http://openmdao.org/ [cited 10 November 2016].

39 Guo, Y., King, R., and Parsons, T., “DriveSE,” URL: http://wisdem.github.io/DriveSE/ [cited 10 November 2016].

40 Fingersh, L., Hand, M., and Laxson, A., "Wind Turbine Design Cost and Scaling Model," NREL/TP-500-40566, National Renewable Energy Laboratory, Golden, Colorado, 2006.

41 Boldea, I., Electric Generators Handbook, Synchronous Generators, CRC Press, 2015.

42 Pyrhonen, J., Jokinen, T., Hrabovcova, V., Design of Rotating Electrical Machines, J. Wiley, 2009.

43 Boldea, I., Variable Speed Generators (The Electric Generators Handbook), CRC Press, 2015.

44 "Markets: Precious and Industrious Metals," URL: http://www.bloomberg.com/markets/commodities/futures/metals [cited 10 November 2016].

45 Metal Pages, URL: https://www.metal-pages.com/ [cited 10 November 2016].

46 Imarc, "Neodymium-Iron-Boron Magnet Market-Industry Trends, Manufacturing Process, Plant Setup, Machinery, Raw Materials, Cost and Revenue," Imarc Group, 2016.

47 Hagerman, G., DOE FOA 415: Topic 2-Award Site Characterization for System Design, Project Update Meeting, June 2012.

48 “Openwind Enterprise,” URL: https://www.awstruepower.com/products/software/openwind/ [cited 10 November 2016].

49 ECN O\&M Tool $\quad$ v4.4, $\quad$ URL: om/?tx_ttnews\%5Btt_news\%5D=1184\&cHash=76f67a886fc3b7104152b194d4d4b36a [cited 10 November 2016].

50 Maness, M., and Maples, B., "NREL Offshore Balance-of-System Model," NREL/TP-6A20-66874, National Renewable Energy Laboratory, Golden, Colorado, forthcoming.

51 Cole, W., Kurup,P., Hand,M., Feldman,D., Sigrin,B., Lantz,E., Stehly,T.,Augustine,C., Turchi,C., O’Connor, P., Waldocj,C., “2016 Annual Technology Baseline (ATB)”, http://www.nrel.gov/docs/fy16osti/66944.pdf.

52 Fullenkamp, P. H., and Holody, D. S., U.S. Wind Energy Manufacturing and Supply Chain, Global Wind Network, 2014.

53 Caroll, J., McDonald, A., and McMillan, D., "Reliability Comparison of Wind Turbines with DFIG and PMG Drive Trains," IEEE Transactions on Energy Conversion, Vol. 30, No. 2, 2015. 